\title{
Educação e direitos das mulheres em tempos de pandemia em Moçambique ${ }^{1}$
}

\author{
Education and women's rights in the time of \\ pandemia in Mozambique
}

Ezra Chambal NHAMPOCA²

Não se pode falar de educação sem amor!

Paulo Freire, Professor, pensador brasileiro.

\begin{abstract}
Resumo
No presente texto discuto alguns aspectos sobre educação e direitos das mulheres em Moçambique, em tempos de pandemia, com enfoque para o ensino superior, por ser docente universitária e ter vivenciado experiências que levantaram reflexóes sobre discriminação de gênero, sobretudo no primeiro semestre de 2020, período que abarcou a suspensão das aulas presenciais e o início das aulas à distância, bem como o apelo governamental do fique em casa! Para desenvolver esta discussão, recorri a conversas informais com quatro docentes, duas mulheres e dois homens e com quatro estudantes, duas do sexo feminino e dois do sexo masculino. Usei também da minha experiência dentro do espaço universitário. A discussão mostrou que em geral, as mulheres não têm tido a possibilidade de gozar plenamente os seus direitos, incluindo os de acesso à educaçáo e que isso se agravou durante a pandemia, mesmo dentro da universidade.
\end{abstract}

Palavras-chave: Educação. Direitos das mulheres. Pandemia. Moçambique.

\begin{abstract}
In this text I discuss some aspects of education and women's rights in Mozambique, in times of pandemic, with a focus on higher education, as a university teacher and having lived experiences that raised reflections on gender discrimination, especially in the first half of 2020 period that included the suspension of face-to-face classes and the beginning of distance classes, as well as the governmental appeal of stay at home! To develop this discussion, I resorted to informal conversations with four teachers, two women and two men and with four students, two female and two male. I also used my experience within the university space. The discussion showed that in general, women have not been able to fully enjoy their rights, including those of access to education, and that this has worsened during the pandemic, even within the university.
\end{abstract}

Keywords: Education. Women's rights. Pandemia. Mozambique.

1 Texto adaptado a partir da apresentaçáo na mesa redonda 2, intitulada Educação e Direitos das Mulheres em Tempo de Pandemia, apresentada no SEMIDU - 2020.

2 Docente na Universidade Eduardo Mondlane, Moçambique, Lattes: lattes.cnpq.br/5287498105582187. ORCID: orcid.org/0000-0002-8522-1608. E-mail: ezranyampoka@gmail.com 


\section{Introdução}

O presente texto resulta de um debate efetuado na mesa redonda 2, durante o SEMIDU/2020, sobre educação e direitos das mulheres em tempos de pandemia. Com esta discussão pretendo apresentar alguns aspectos relativos aos direitos das mulheres em Moçambique, sobretudo em tempos de pandemia, com enfoque para o Ensino superior, em virtude de eu ser professora universitária e ter vivenciado experiências que levantaram reflexóes sobre discriminação de gênero, particularmente no que respeita ao primeiro semestre de 2020, período que abarcou a suspensão das aulas presenciais e o início das aulas à distância, bem como o apelo governamental do fique em casa!

O governo de Moçambique tomou a decisão de suspender as aulas presenciais em todos os subsistemas de ensino, a 17 de março 2020, antes mesmo de ocorrer o primeiro caso de Covid-19, como forma de travar a propagação da Covid-19. Com o aparecimento do primeiro caso oficial da Covid-19, a 22 de março de 2020, as medidas foram reforçadas. Cancelou-se a emissão de vistos e foram reforçadas medidas de controlo de entradas de pessoas e o rastreamento dos que chegavam do exterior e que deviam seguir em quarentena domiciliar. A medida que o número de casos subia, embora de forma lenta, as medidas de prevenção eram também incrementadas.

No dia 01 de Abril foi decretado o estado de emergência de 30 dias que viria a ser prorrogado por 3 vezes consecutivas. Essas medidas contribuíram para que as aulas do primeiro semestre e parte do segundo semestre decorressem na modalidade à distância.

No texto, apresento de forma prática, algumas diferenças de responsabilidades e de responsabilização, no agir diário, entre mulheres e homens, quer de forma geral, assim como particularmente, quer no espaço fora, quer dentro do espaço universitário. Para desenvolver esta discussão, recorri fundamentalmente a dois recursos, 1) conversas informais com quatro docentes, duas mulheres (Docentemulher $A$ e Docente-mulher B) e dois homens (Docente-homem $C$ e Docentehomem $D$ ) e com quatro estudantes, duas do sexo feminino (Estudante-mulher $A$ e Estudante-mulher B) e dois do sexo masculino (Estudante-homem Ce Estudantehomem $D$ ). As conversas basearam-se na seguinte pergunta de partida: comolqual foi a sua experiência de lecionação durante o periodo de confinamento? - Para docentes e, comolqual foi a sua experiência de ter aulas durante o periodo de confinamento? Para estudantes.

As respostas fornecidas pelos docentes e pelos estudantes permitiram, de forma representativa, observar o que se passou entre docentes-mulheres e docentes-homens e entre estudantes-mulheres e estudantes-homens. 2) Usei, igualmente, da minha experiência de professora-pesquisadora-mulher-ativista-mãe, 
experiência que me tem permitido estar por dentro, vivenciando, observando e problematizando muitos dos aspectos refletidos neste texto.

O texto organiza-se em seis seções, a saber: $1^{a}$ seção é da introdução; a $2^{a}$ disserto, de forma breve, sobre a base sexista da educação em Moçambique; a $3^{a}$ seção passo um olhar breve sobre a situação da educação e direitos das mulheres em tempos de pandemia, a partir da comparação das experiências das mulheres e dos homens (docentes e estudantes) e a partir da minha própria experiência; na 4a apresento a Associação Sororidade, criada a partir de minha experiência de luta contra discriminação de gênero em sala de aula; na $5^{a}$ seção deixo algumas liçóes a tirar a partir do contexto da Covid-19 e, por fim, na $6^{a}$ seção, as consideraçôes finais.

\section{Base sexista e educação das mulheres em Moçambique}

A educação em Moçambique ainda possui uma base sexista, desde o ensino primário até ao universitário, porque as nossas sociedades, no que diz respeito ao acesso à educação, seja primária, secundária ou universitária, ainda dão prioridade aos meninos em prejuízo das meninas. Durante muito tempo, no contexto moçambicano, privilegiou-se a ida à escola dos meninos em relaçáo as meninas. Em situaçóes em que houvesse oportunidades limitadas para o acesso à escola, a prioridade eram os meninos e não as meninas, porque culturalmente, acredita-se que a menina quando cresce, casa-se e passa a pertencer a outra família, a do marido. Isso faz com que em muitas famílias acredite-se que a menina ao se casar, deixa de pertencer àquela família, então o melhor é preparar o menino que vai continuar na família até a velhice e entấo ele tem a prioridade de ir à escola para que no futuro cuide da família e não a menina que no futuro vai abandonar a família para pertencer a outra, a nova família, a do casamento. Este pensamento é ilusório, pois na prática, dependendo do caráter de cada um, vê-se na sociedade moçambicana, tanto mulheres, assim como homens que cuidam seus familiares, não sendo por isso, uma questão de gênero, mas sim de caráter

Portanto, tudo inicia com a ilusória ideia de que ao se casar, a menina deixa de pertencer à família de origem e passa a pertencer à família do marido, por isso, não há necessidade de investir nela. Esta ideia mostra o quanto a questáo sexista e discriminatória que prejudica meninas e mulheres e, consequentemente a sua educação e seus direitos como mulheres, não começa com a pandemia, a pandemia só veio agravar a situação e mostrar o quão isso é prejudicial para os direitos das mulheres, sobretudo o direito de escolher aquilo que elas querem ser e fazer, como sujeitas de suas vidas. 
Uma das formas de ilustrar o sexismo na educação que menciono acima, é buscar a sabedoria da literatura, sobretudo a escrita por mulheres, em Moçambique. Dentre os vários exemplos, trago para este universo, a escritora moçambicana, Lília Momplé. Lília escreveu vários contos, mas o nosso exemplo vem do conto, $O$ sonho de Alima, extraído do livro Os olhos da cobra verde. Nele, Momplé apresenta-nos uma menina-mulher-protagonista corajosa, uma mulher que contraria todo o sistema patriarcal e machista para tentar viver sua vida a partir das próprias decisóes.

Em $O$ sonho de Alima, Alima, ainda no ventre de sua progenitora, recusa-se nascer. Sua mãe tem um longo e difícil trabalho de parto. A interpretação disso é que Alima nega-se a vir a este mundo em que a mulher é tida como um ser secundário. Vejamos o extrato abaixo:

No conto "O sonho de Alima", contido no mesmo livro, também encontramos ecos do empoderamento do feminino nas posiçôes, decisôes e características dadas às personagens. Alima, protagonista do conto, já nasce rebelde. Durante o seu parto, recusa-se a nascer, causando sofrimento à mãe - parturiente. A matrona presente para assistir o parto de Alima se revolta: "- É uma criança obstinada... recusa-se a deixar a barriga da máe queixa-se a matrona, [...].” A irmá da mãe da bebê, porém, contrapôe-se à matrona e diz-lhe: "Não é uma criança obstinada, é uma criança que sabe o que quer. Ela sabe que no ventre da mãe está melhor do que nesta vida! - Responde a futura khulo ${ }^{3}$ que veio de longe, propositadamente para assistir ao parto da irmá mais nova (AVIZ e NHAMPOCA, 2017, p.09).

Ao atingir a idade escolar, Alima tem o desejo de ir à escola, mas por ser menina, o pai não permite, apenas seus irmãos meninos, têm direito de ir à escola. A mãe da Alima que também está no papel secundário na família, apercebe-se da inteligência da filha, pois ela que aprende fácil e rapidamente as letras, ao usar, às escondidas, os livros dos irmãos - meninos, privilegiados, com oportunidade de ir à escola, implora ao seu marido, pai para que esta tenha também oportunidade de estudar, mas sem sucesso! O privilégio de estudar é dos meninos. À Alima resta o papel de ajudar a mãe nos afazeres domésticos - papel culturalmente reservado às mulheres.

Dando seguimento ao conto, quando Alima cresce, dá-se a possibilidade de escolher o próprio marido e aí ela mostra que ela tem o poder de escolher o que

Significa tia, irmã mais velha da mãe. 
ela quer e no mesmo sentido de luta permanente, matricula-se numa escola de alfabetização de adultos, para em fim, realizar o desejo amputado na infância. Como se pode verificar, Alima só tem a oportunidade de ir à escola quando atinge a maioridade e luta pelo direito de decidir por si.

Sobre o extrato acima, Nhampoca e Aviz (2017), afirmam que Lília Momplé usa a personagem Alima para transmitir uma forte mensagem feminista, pois, Alima além de só nascer no tempo em que ela decide nascer, também leva uma vida que contraria todo um sistema de tradiçáo patriarcal. Ela tem opiniáo própria, toma suas próprias decisóes para sua vida. Enquanto dependia dos pais, essa ousadia da Alima foi velada, mas quando cresceu, escolheu o próprio marido, decidiu estudar como forma de realizar um sonho que só não se realizara antes porque o pai sempre preferiu que apenas os irmãos-homens fossem à escola, apesar dos vários apelos da máe de Alima.

A história de Alima repete-se em milhares de meninas moçambicanas que ainda pequenas, são colocadas fora do caminho da escola e, muitas vezes, essas meninas nem sequer têm a sorte de ter a força de luta da Alima, terminando sem a possibilidade de se alfabetizar, formar-se e ter um futuro promissor. O conto de Momplé mostra o quão a mulher pode ser poderosa apesar da discriminação secular, predominantemente, embasada na cultura.

Em um debate realizado na Televisão de Moçambique, no programa Quinta à noite, sobre o ensino primário em Moçambique, em 2020, o representante do Ministério da Educaçáo e Desenvolvimento Humano apresentou dados que mostraram que nos últimos anos, diferentemente do que ocorriam no passado, no ensino primário há um número elevado de meninas que ingressam para a escola. Acrescentou que o número de ingresso de meninas chega a superar o dos meninos, contudo, à medida que essas meninas crescem, diminui o seu direito à educação, devido a vários constrangimentos e condicionalismos culturais, sobretudo nas regiōes rurais, onde reside a maior parte da população moçambicana (66.6\%). Os constrangimentos e condicionalismos culturais que impedem a educação das meninas são de várias ordens, destacando-se a violência sexual de meninas, os casamentos prematuros, a descontinuidade do acesso à educação, a sobrecarga dos trabalhos domésticos, entre outros.

A questão da violação sexual de meninas é gritante em Moçambique. Organizaçóes governamentais e não-governamentais têm-se desdobrado no combate a este mal. Contudo, dados mostram que é ainda um problema grave no país e que prejudica sobremaneira os direitos das meninas e das mulheres. Dados do departamento de atendimento à família e menores vítimas de violência, do comando geral da polícia de Moçambique mostraram que durante o primeiro 
semestre de 2020, 866 crianças $^{4}$ foram vítimas de algum tipo de crime contra a liberdade sexual, mas como podem observar, na tabela 1, abaixo, desse número, 855 são meninas e apenas 11 são meninos, deixando claro que as meninas são as maiores vítimas desse crime.

Tabela 1: Crimes contra a liberdade sexual por categoria de vítimas no $1^{\circ}$ semestre de 2020

\begin{tabular}{l|c|c|c|c|c|c|c|c|c|c|c}
\hline \multirow{2}{*}{ Tipologia criminal } & \multicolumn{3}{|c|}{ Crianças } & \multicolumn{3}{c|}{ Adultos $^{5}$} & \multicolumn{3}{c|}{ Pessoa idosa $^{6}$} & \multicolumn{3}{c}{ Total } \\
\cline { 2 - 11 } & Rapazes & Rapariga & Total & H & M & Total & H & M & Total & H & M \\
\hline Violação & & 364 & 364 & & 176 & 176 & & 16 & 16 & 0 & 556 \\
\hline $\begin{array}{l}\text { Violação Menor de } \\
12 \text { anos }\end{array}$ & 5 & 268 & 273 & & & & & & & 5 & 268 \\
\hline $\begin{array}{l}\text { Atos sexuais com } \\
\text { Menores }\end{array}$ & 6 & 143 & 149 & & & & & & & 6 & 143 \\
\hline $\begin{array}{l}\text { Atentado ao Pudor } \\
\text { Assédio sexual }\end{array}$ & 63 & 63 & & 5 & 5 & & & & 0 & 68 \\
\hline $\begin{array}{l}\text { Lenocínio } \\
\text { Corrupção de } \\
\text { Menores }\end{array}$ & 15 & 15 & & & & & & & 0 & 15 \\
\hline \begin{tabular}{l} 
Total \\
\hline
\end{tabular} & 11 & 855 & 866 & & 181 & 181 & 0 & 16 & 16 & 11 & 1052 \\
\hline
\end{tabular}

Fonte: Departamento de atendimento à família e menores vítimas de violência, comando geral da polícia.

Apesar de o meu foco ser os dados referentes a meninas e meninos, é importante observar que em termos globais, as mulheres (meninas, mulheres e idosas) são as categorias que mais sofreram violência sexual no período em questão.

Os casamentos prematuros também introduzem desigualdades de oportunidades no que concerne ao acesso à educaçáo, em Moçambique, colocando as meninas, maiores vítimas dos casamentos prematuros, fora da rota do sistema educativo (NHAMPOCA, 2020).

A descontinuidade no acesso à educação ocorre, por exemplo, quando crianças, adolescentes e jovens concluem um certo nível de escolaridade e não encontram escolas ou vagas dos níveis subsequentes, na sua regiáo de origem, o que faz com que as crianças tenham de percorrer longas distâncias para alcançar as novas escolas. Este

\footnotetext{
4 Em Moçambique considera-se criança o indivíduo com idade compreendida entre 0 e 17 anos.

5 Em Moçambique considera-se adulto o indivíduo com idade compreendida entre 18 e 59 anos.

6 Em Moçambique considera-se pessoa idosa o indivíduo com idade a partir dos 60 anos em diante.

7 Em Moçambique a palavra rapariga tem o significado de menina.
} 
factor, apesar de afetar meninos e meninas, tem maiores consequências negativas para as meninas, porque elas correm maior risco de ser violentadas ao longo do caminho para escola ou de regresso à casa. Muitas vezes, como forma de evitar esse risco, muitas famílias optam por interromper os estudos das meninas. Outrossim, quando a menina conclui o ensino primário, muitas vezes não tendo como continuar porque a escola de continuidade fica distante da família, à medida que esta menina vai crescendo, atinge a adolescência e/ou tem a sua primeira menstruação, é vista como uma mulher adulta, que já pode e na pior das hipóteses, já deve se casar, ser mãe ou mesmo ser obrigada a se juntar e/ou a casar-se prematuramente, muitas vezes com um homem adulto, reduzindo dessa forma, a presença das meninas na escola, uma vez que o casamento prematuro significa que esta menor, para além de estar sujeita à gravidez precoce, passa a ser obrigada a cuidar do filho, do marido, dos familiares do marido e dos afazeres domésticos.

A exploração do trabalho não remunerado das mulheres e de crianças está presente também em Moçambique. Contudo, é preciso destacar que a sobrecarga do trabalho doméstico sobre as meninas e mulheres, configura um grande atropelo aos seus direitos e as coloca num papel servil, muitas vezes sustentado pela invocação de aspectos culturais, papéis de gênero e um fazer por amor, camuflado numa lógica de exploração, como forma de manter e garantir continuidade dos privilégios da cultura patriarcal e capitalista que se beneficia dessa exploração.

As meninas sáo obrigadas pelos ditames da cultura, pela sociedade e pela própria família a participar de forma ativa nas atividades domésticas de cuidado com a casa e de outras pessoas da família, sobretudo homens, menores e adultos. O exemplo que segue, extraído de uma entrevista ao Jornal Generus, ilustra, de alguma forma esse facto.

Dar exemplos concretos e típicos da nossa realidade foi uma estratégia usada pela pesquisadora para elucidar os leitores sobre a filosofia de atuação do patriarcado na construção das discriminaçóes de gênero $e$, consequentemente, na cristalização de assimetrias sociais entre homens e mulheres. Vamos imaginar um casal que tenha dois filhos: quando a menina é a mais nova, os pais ou as outras pessoas da família a obrigam a servir o irmão, dizem que deve servir ao irmão porque ela é a mais nova, entâo tem que obedecer e servir ao irmão mais velho. Mas, quando a menina é a mais velha, dizem que deve servir e cuidar do irmáo mais novo porque ela é mais velha e nunca há situaçóes em que se diz que o rapaz deve fazer um chá, um arroz, dar banho, etc. para a irmá mais nova ou mais velha, coisas que obrigam as meninas a fazer. Portanto, não há reciprocidade. A menina, 
a futura mulher nunca tem a sua vez de ser servida e isso só acontece exatamente por ela ser menina - logo, temos aí uma discriminação de gênero ' (NHAMPOCA, 2021, in JORNAL GENERUS, p.05).

Os casamentos prematuros, a violência sexual, a violência doméstica, a sobrecarga dos trabalhos domésticos, entre outros males que impossibilitam as meninas de continuar os estudos mutilam os direitos delas como crianças e como seres humanos e reforçam o sexismo na educação em Moçambique. E, porque a pandemia só veio agravar a situação de discriminação de gênero, na seção que segue, debruço-me sobre a educação e direitos das mulheres em tempos de pandemia em Moçambique.

\section{Pandemia e Direitos das Mulheres no Ensino superior}

Minha experiência na vida e na universidade mostra que a discriminação de gênero não ocorre apenas na esfera doméstica, mas também em outros espaços, como por exemplo, a universidade. A presença da mulher no meio universitário continua muito baixa, se comparada com a presença masculina. Em termos de ocupação de lugares de liderança também verifica-se um reduzido número de mulheres que ocupam cargos de liderança (MOÇAMBIQUE, 2013). Na Universidade Eduardo Mondlane, a mais antiga do país, o número de docentes do sexo feminino situa-se abaixo dos $30 \%$, como mostra a tabela que segue.

Tabela 2: dados estatísticos sobre docentes na Universidade Eduardo Mondlane

\begin{tabular}{l|r|r}
\hline Descrição & Número & Percentagem \\
\hline Candidatos & 1226 & $74 \%$ \\
\hline Homens & 433 & $26 \%$ \\
\hline Mulheres & 1659 & $100 \%$ \\
\hline Total & 1584 & $95 \%$ \\
\hline Nacionalidade & 75 & $5 \%$ \\
\hline Moçambicana & 1659 & $100 \%$ \\
\hline Estrangeira & & \\
\hline Total & 1169 & $70 \%$ \\
\hline Tipo de contrato & 490 & $30 \%$ \\
\hline Tempo Inteiro & 1659 & $100 \%$ \\
\hline Mulher & \multicolumn{2}{|c}{} \\
\hline Total &
\end{tabular}

Fonte: Universidade Eduardo Mondlane < https://www.uem.mz/index.php/90-sobre-a-uem/uem-em-numeros/uemem-numeros-2012/203-estatisticas-sobre-docentes?mid=151\&limit-start=115 >. 
Os dados da tabela 2 mostram que dos 1.659 docentes que a Universidade Eduardo Mondlane possui, apenas 433 (26\%) são mulheres. É verdade que, comparando com o que ocorria há algumas décadas, o cenário da presença e atuação da mulher na universidade tende a melhorar, mas, tendo em conta que a população moçambicana é maioritariamente constituída por mulheres, cerca de 52\% (INE), essa percentagem é ainda insignificante e isso influi e afeta negativamente, no direito à educação e participação universitária das mulheres.

$\mathrm{O}$ aspecto descrito acima diz muito sobre a base sexista da educação no país que já foi descrita anteriormente; se as meninas não passam do ensino primário para adentrar o secundário como é que vão chegar à universidade? Então, isto significa que precisamos implementar com mais seriedade as políticas já existentes e plasmadas em vários documentos, tais quais, Plano Quinquenal do Governo de Moçambique, os Objetivos de Desenvolvimento Sustentável e o Plano Nacional de Ação para Criança, no que diz respeito à educação para que mudemos a história das mulheres e do seu acesso à educação, desde o ensino primário, secundário até à universidade.

Em tempos de pandemia, assim como de outras dificuldades sociais, os direitos das mulheres são os menos observados e a sobrecarga de outros trabalhos e ocupaçóes domésticas colocam as mulheres (docentes e estudantes) sempre em desvantagens, em relação aos homens da mesma categoria. A fraca capacidade de autossustento, muitas vezes derivada de aspetos resultantes da discriminaçáo de gênero, tais quais, baixa escolaridade, menos presença no mercado formal e massiva no informal, tendo este último ficado deveras ameaçado com a ordem do fique em casa motivada pela pandemia da Covid-19.

A partir de conversas com 4 docentes ( 2 mulheres e 2 homens) e 4 estudantes ( 2 mulheres e 2 homens), trago, apenas de forma representativa, as diferenças entre a situaçáo de homens e mulheres no que respeita ao acesso às aulas à distância, sobretudo no que respeita ao primeiro semestre de 2020, parte do ano em que se observaram os sucessivos estados de emergência, em Moçambique, depois de aulas presenciais terem sido suspensas em Março do mesmo ano, como forma de travar a pandemia da Covid-19. No período descrito, as aulas passaram a ser lecionadas à distância, num cenário de muita precaridade das instituiçóes de ensino, despreparo por parte de estudantes, pessoal técnico administrativo, docentes e gestores, baixa qualidade e preços elevados de internet. Abaixo seguem as perguntas e extratos das respostas fornecidas pelos participantes ${ }^{8}$ :

8 Os participantes foram nomeados apenas por docente A, B, C e D e por estudante A, B C e D, como forma de preservar os docentes e estudantes participantes. 


\section{Pergunta de partida para docentes: como/qual foi a sua experiência de lecionação durante o período de confinamento?}

\section{Docente-mulher A}

Com a pandemia, tudo se complicou. Trabalhar a partir de casa não é fácil. Primeiro porque a internet é muito cara e a universidade não fornecia internet. Na universidade havia internet, mas a ordem era de ficar em casa. Eu como docente conseguia, mas os meus estudantes não. Eu nunca tinha a turma completa. Os estudantes afirmavam não possuir capacidade financeira para adquirir dados de internet. Para mim como docente e pesquisadora, tornou-se difícil esta situaçáo, antes da pandemia, fazia o trabalho de preparação das aulas e de algumas pesquisas na universidade, durante o confinamento não tinha como estar lá. E trabalhar em casa, para nós

Mulheres, é sempre complicado, não importa o nível de formação. Por causa da pandemia, durante o confinamento, dispensei a empregada e não me restou outra alternativa a não ser dividir o meu tempo entre as actividades de docência e as atividades domésticas, limpar a casa, preparar as refeiçóes etc. e a internet também não é de grande qualidade, há dias que mesmo tendo dados, a rede não funcionava e tivemos que adiar as aulas [...].

\section{Docente-mulher B}

[...], a situação foi assustadora. Eu tenho filhos pequenos e com o encerramento das aulas estavam os três em casa e o meu esposo também, apesar de ter a senhora que ajuda no cuidado com a casa e com as crianças, etc., não foi fácil. Há vezes que estava em plena aula e o meu filho mais novo vinha e precisa de mim, parava. Os meus estudantes já sabiam até, porque às vezes tinha que parar as aulas para atender as crianças. Os estudantes também tinham algumas dificuldades, reclamavam a falta de dispositivos, de internet para participar das aulas. Mas para mim, o maior problema era a falta de concentração para o trabalho em casa. Há vezes que tinha que ajudar as crianças com os seus trabalhos escolares e dar a elas mais atenção para não que o confinamento fosse mais leve para elas, era muita tarefa junta.

\section{Docente-homem C}

[...]. A experiência foi difícil, mas não havia alternativa, era mesmo nos adaptarmos ao dito novo normal. Não esperávamos que de repente passássemos a dar aulas à distância. $\mathrm{O}$ maior problema com as aulas à distância eram as ausências dos nossos estudantes, não conseguiam participar de todas as aulas por falta de internet e isso atrasava tudo. Mesmo nós que somos docentes, há vezes que não tínhamos internet, quanto mais os estudantes! Muitos não trabalham [...]. 


\section{Docente-homem D}

[...], foi uma experiência nova e difícil, sobretudo pela má qualidade da internet, muitas vezes, a rede caía. Os estudantes náo participavam todos de todas as aulas, alegavam ter dificuldades com algumas plataformas recomendadas, tal como o Zoom, mas também que não possuíam celulares e computadores compatíveis para as plataformas. A outra dificuldade, náo menos importante, é que houve alguns conteúdos não foram fáceis de lecionar à distância $[. .$.$] .$

\section{Pergunta de partida para estudantes: como/qual foi a sua} experiência de ter aulas durante o período de confinamento?

\section{Estudante-mulher A}

Durante a quarentena, as aulas foram um pouco complicadas. O grande problema para mim, foi porque eu vivo num bairro com problemas sérios de energia, perdi muitas aulas porque ficávamos muitos dias sem energia e alguns professores não entendiam esses problemas de falta de energia, internet. Há vezes que não tinha megas ${ }^{9}$ para participar das aulas, mas também havia dificuldades nas aulas no Zoom, porque eu não sabia usar. Muitos professores usavam o whatsapp, nesse caso era mais fácil. Aprendi a usar o Zoom para não perder aulas. Percebi também que muitos colegas faltavam as aulas por falta de megas, alguns tinham dificuldades de baixar os documentos no telefone, alguns porque os telefones náo eram adequados outros por falta de conhecimento de como baixar documentos, mesmo [...]. Às vezes tinha ocupaçóes e não conseguia fazer todos os trabalhos da faculdade, porque quando você está em casa, sempre surgem coisas para fazer e às vezes como mulher, é difícil deixar e não fazer. Você começa a fazer achando que tem tempo suficiente, quando vê o tempo já se foi, enquanto quando está na faculdade não há isso, é só estudar.

\section{Estudante-mulher B}

[...], eu sou estudante e sou mãe e trabalhadora, dou aulas numa escola primária. Então, durante o confinamento, eu tinha que elaborar exercícios e mandar para a escola para os meus alunos, ajudar a minha filha a resolver as fichas que recebia da escola dela e participar das minhas aulas na universidade. Não foi fácil, pensei em desistir, porque também tinha dificuldades de internet, então às vezes perdia 
aulas e tinha que pedir informações aos colegas. Então não foi fácil, quando ouvi que passaria a estudar em casa, pensei que seria bom, mas em duas semanas, eu já estava esgotada. Era muita coisa a fazer e ainda por cima o medo da pandemia. Os trabalhos domésticos de casa atrapalharam muito porque estava toda a gente em casa, ninguém saia e eu tinha que me virar para fazer e ainda estudar.

\section{Estudante-homem C}

A maior dificuldade que enfrentei foi não ter um bom telefone nas primeiras semanas das aulas à distância. Valeu a atenção de alguns colegas que depois me passaram os conteúdos. Outro problema era com algumas matérias que não conseguíamos entender via online e nem todos os professores tinham paciência de voltar a explicar, a saída for criar um grupo para passarmos a nos ajudar, mesmo à distância. Foi esse grupo que me passava os apontamentos quando não tinha telefone. Quando comprei um telefone bom, tudo melhorou e deixei de ser totalmente dependente dos colegas. Comecei a participar ativamente das aulas. Em casa havia um bom ambiente de estudo e a minha família sabia que eu tinha que estudar e respeitava, [...].

\section{Estudante-homem D}

A minha experiência de aulas durante a quarentena foi desafiadora. Antes da pandemia eu não usava redes sociais, porque náo gosto, então quando começamos as aulas à distância, tive que baixar o whatsapp e participei de algumas aulas via Zoom. Só um professor usava Zoom, todos usavam whatsapp e houve um professor que desapareceu, não deu aulas à distância, só depois, quando retomaram as aulas presenciais, o professor voltou a dar-nos aulas. O meu e-mail estava desativado porque não usava há muito tempo, então tive que reativar. Tirando isso, apesar de ter sido difícil adaptar-me às novas formas de estudar, encarei o desafio e aproveitei o tempo de ficar em casa para estudar seriamente. [...].

A partir das respostas obtidas, analisei, de forma breve, três aspetos, a saber: 1) Disponibilidade de tempo/(in)existência de tarefas que interferem nas atividades das aulas à distância; 2) Domínio das ferramentas usadas para as aulas à distância e 3) Capacidade de aquisição de internet e dispositivos para as aulas à distância. 


\section{Disponibilidade de tempo/(in)existência de tarefas que interferem nas actividades as aulas à distância}

De uma forma geral, os homens possuem múltiplas vantagens em relação as mulheres, quando o assunto é a tranquilidade para realizar as atividades escolares. Só nas breves conversas analisadas acima, verifica-se que, no que respeita à disponibilidade de tempo para a lecionaçáo e ter aulas, as docentes e as estudantes, na sua totalidade, fizeram referência à obrigatoriedade de cuidar dos filhos e das outras pessoas da família, de realizar atividades domésticas, auxiliar os filhos nas tarefas da escola e o quanto isso interfere nas suas atividades, tanto de lecionaçáo, assim como de aprendizagem, enquanto para os homens, docentes e estudantes, essa dificuldade parece passar muito longe de fazer parte de suas preocupaçóes e nem chega a ser mencionada por eles.

Em tempos de pandemia, a maior preocupação dos docentes e dos estudantes (homens) são as aulas, as ferramentas usadas, a aquisiçâo de dados de internet, mas para as docentes e para as estudantes (mulheres) para além dessas preocupaçóes, também se preocupam em garantir o cuidado doméstico e sanitário de suas famílias, já que a sociedade empurra esse fardo para as mulheres.

Em Moçambique, a garantia do cumprimento das medidas de prevenção e combate à Covid-19, nas famílias e na sociedade é colocada nas mãos das mulheres e há, entre essas mulheres, educadoras e educandas. Então, ao mesmo tempo que se secundariza a mulher como sujeito na sociedade, reconhece-se que sem o seu trabalho valioso, seguramente, o país colapsaria, reconhece-se que sem elas as medidas de proteçâao caem por terra, pois são elas que cuidam, que sabem como é que se deve fazer, até o simples ato da lavagem das mãos. Portanto, a sobrecarga de tarefas e a falta do apoio dos outros membros das famílias na realização do trabalho doméstico influencia negativamente o acesso efetivo à educação.

\section{Domínio das ferramentas usadas para as aulas à distância}

Neste quesito, embora dentro da universidade, tenha experienciado casos de estudantes e docentes que afirmavam não dominar as ferramentas usadas para as aulas, das oito conversas presentes neste texto, percebe-se que são os estudantes que mais se queixam da falta de domínio das ferramentas, sejam homens ou mulheres. Contudo, ao cruzar a disponibilidade de tempo dos estudantes homens em relação às estudantes mulheres, é notável que aqueles dispóem de mais tempo e tranquilidade para praticar e desenvolver um nível de literacia sobre as ferramentas em relação às suas colegas. 


\section{Capacidade de aquisição de internet e dispositivos compatíveis para as aulas à distância}

Sobre a capacidade de aquisição de internet e dispositivos compatíveis, os docentes queixa-se menos em relação aos estudantes. Dentro da universidade, esse facto verificou-se de igual forma, pois, apesar de os docentes também terem-se queixado do facto de universidade não disponibilizar um subsídio de internet quando tinham que lecionar a partir de casa, foram os estudantes que mais mostraram incapacidade de aquisição, o que pode estar aliado ao facto de os docentes, em geral, possuírem alguma estabilidade financeira em relação aos discentes.

Neste tópico, destaco que em geral, em Moçambique, por causa da discriminação trabalhista e também da baixa escolaridade, muitas mulheres possuem um fraco poder de compra, dependendo, muitas vezes, dos parceiros, pais, irmãos, entre outros, maioritariamente homens. Se se considerar este fato, pode se pensar que as estudantes podem ter passado por mais situaçóes de incapacidade de compra de produtos básicos e também de internet, assim como de dispositivos compatíveis para a participação nas aulas.

Algumas estudantes que frequentam a universidade sustentam-se através de pequenas vendas que realizam em vários locais, em casa, na universidade, nos mercados, ou mesmo através do mukheru ${ }^{10}$. Com a pandemia, com o fecho das fronteiras e com a ordem para o confinamento, essas mulheres não podiam realizar estes serviços informais, o que precarizou ainda mais a sua capacidade de autossustento que já era precária antes da pandemia.

Se os direitos das mulheres já não são respeitados fora da pandemia, a pandemia veio agravar a situação e a experiência passada durante as aulas à distância evidencia esse fato. De um dia para o outro tivemos que passar para as aulas à distância. E não havia condiçóes. Nas minhas turmas, notei maior desgaste, carência e mais dificuldades de acesso às tecnologias para esta modalidade de ensino nas estudantes que nos seus colegas, portanto, por via dessa multiplicidade de dificuldades, elas tiveram menos acesso à educaçáo se comparados aos estudantes homens.

A violência doméstica em tempos de pandemia pode, igualmente ter interferido no acesso aos direitos das mulheres, incluindo o de acesso à educação. Embora nenhum dos participantes tenham mencionado uma experiência de

10 Trabalho de venda de produtos comprados a grosso na África do Sul ou Reino do Eswatini, para revender em Moçambique. 
violência doméstica, se calhar porque a pergunta de partida não direcionou para esse aspeto, é preciso indicar que, no país, comparando com os homens, as mulheres sofreram mais violência durante o confinamento. Os dados apresentados na tabela 3 ilustram os números de casos de violência doméstica, no primeiro semestre de 2020, que abarca o período de confinamento.

Tabela 3: Casos de Violência Doméstica por Categorias de Vítimas, no $1^{\circ}$ semestre de 2020

\begin{tabular}{|c|c|c|c|c|c|c|c|c|c|c|c|}
\hline \multirow[b]{2}{*}{$\begin{array}{l}\text { TIPOLOGIA } \\
\text { CRIMINAL }\end{array}$} & \multicolumn{3}{|c|}{ CRIANÇAS } & \multicolumn{3}{|c|}{ ADULTOS } & \multicolumn{3}{|c|}{ IDOSOS } & \multicolumn{2}{|c|}{ TOTAL } \\
\hline & 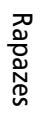 & 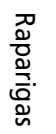 & $\stackrel{\vec{O}}{\underline{\underline{I}}}$ & $\begin{array}{l}\text { I } \\
\text { O } \\
\stackrel{3}{D} \\
\stackrel{D}{D}\end{array}$ & 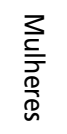 & $\stackrel{\vec{O}}{\underline{\Phi}}$ & $\begin{array}{l}\text { T } \\
\text { O } \\
3 \\
\text { D } \\
\stackrel{D}{3}\end{array}$ & 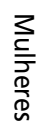 & $\begin{array}{l}-1 \\
\underline{O}\end{array}$ & 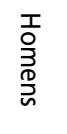 & 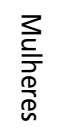 \\
\hline V.F. Simples & 63 & 102 & 165 & 451 & 3177 & 3628 & 49 & 62 & 111 & 563 & 3341 \\
\hline V.F. Grave & 6 & 6 & 12 & 66 & 379 & 445 & 2 & 19 & 21 & 74 & 404 \\
\hline V. Psicológica & 1 & 3 & 4 & 217 & 907 & 1124 & 45 & 86 & 131 & 263 & 996 \\
\hline V. Moral & & 2 & 2 & 11 & 77 & 88 & & & & 11 & 79 \\
\hline V. Patrimonial & & 1 & 1 & 214 & 498 & 712 & 22 & 61 & 83 & 236 & 560 \\
\hline V. Social & & & & 2 & 14 & 16 & & & & 2 & 14 \\
\hline $\begin{array}{l}\text { Cópula Não } \\
\text { Consentida }\end{array}$ & & & & & 18 & 18 & & & & 0 & 18 \\
\hline $\begin{array}{l}\text { Cópula C. } \\
\text { Transmissão. Doenças }\end{array}$ & & & & 3 & 22 & 25 & & & & 3 & 22 \\
\hline Total & 70 & 114 & 184 & 964 & 5092 & 6056 & 118 & 228 & 346 & 1152 & 5434 \\
\hline
\end{tabular}

Fonte: Departamento de atendimento à família, menores vítimas de violência comando geral da polícia.

Com os dados acima pretendo mostrar que as mulheres (raparigas, mulheres e idosas) sofreram mais violência doméstica durante o confinamento em relação aos homens (rapazes, homens e idosos). O total de meninas vítimas de violência doméstica foi de 114, mulheres 5.092 e de idosas, 228, contra 70 de meninos, 964 de homens e 118 de idosos.

Nhampoca (2020, no prelo), ao analisar os mesmos dados, afirma que se se tomar em consideração que durante o confinamento, uma das medidas de prevenção à Covid-19 emanadas pelas autoridades da saúde e governamentais, era fique em casa, pode-se inferir que algumas vítimas de violência tenham 
tido impossibilitadas de se apresentar às esquadras de forma presencial para reportar crimes de violência doméstica e os mecanismos de denúncia através de linhas telefónicas, implementados pela polícia nos gabinetes de atendimento à família e menores vítimas de violência, podem ter sido de difícil acesso por parte das vítimas, uma vez que durante o confinamento, a convivência com os potenciais agressores aumentou. É igualmente possível que tenha havido falta de informação sobre a possibilidade de realizar denúncias por telefone, o que significa que mais mulheres podem ter sofrido violência, para além dos números representados nas estatísticas.

Estes números revelam que se as mulheres já eram as maiores vítimas da violência doméstica antes da pandemia, durante a pandemia, isso náo se alterou, continuaram sendo as que mais sofrem por este mal, o que sem dúvidas interfere negativamente nas suas atividades educativas, tanto como docentes assim como estudantes, se considerarmos que a violência doméstica ocorre em todos os extratos sociais.

Todos estes cenários contribuem para a inviabilização dos direitos das mulheres em tempos de pandemia. Basta questionarmos, como é que uma mulher que é ou foi vítima da violência doméstica irá continuar a ministrar e a participar das aulas à distância, sem que os traumas físicos e psicológicos interfiram no seu agir docente e estudante? Como é que essa mulher irá retornar e se sentir confortável no processo de ensino e aprendizagem e sentirse em segurança, em sua casa, onde é violentada?

O filósofo moçambicano Severino Ngoenha, em uma de suas intervenções públicas, afirmou que a pandemia vinha mostrar as desigualdades sociais existentes e com elas percebemos que estamos juntos, mas não misturados. De facto, "a pandemia não é a mesma para todos os países, nem a mesma para todos dentro de um mesmo país ou da mesma cidade [...]" (LIMA 2020, p. 1). A partir das análises destes dois autores, afirmo seguramente que para além das desigualdades ditadas pelos lugares geográficos em que cada um de nós se encontra, das desigualdades sociais, entre ricos e pobre, patróes e empregados, a pandemia não é igual para homens e mulheres, dentro do mesmo planeta, continente, país, da mesma cidade, dentro da mesma casa e até mesmo dentro da mesma universidade. Ela é mais pesada para as mulheres porque têm atividades acrescidas, múltiplas jornadas, o que minora o gozo dos seus direitos, no geral e em particular à educação.

Durante o confinamento, por via do trabalho que realizo, através da Associação Sororidade, vivenciei de perto situaçóes de mulheres vítimas de violência doméstica, entre docentes, estudantes e outras. A seguir deixo algumas notas breves sobre a associação. 


\section{A associação Sororidade Moçambique e os direitos das mulheres}

Sou mulher. E Sou mãe de três meninas, então engrossei o movimento de mulheres trazendo mais três meninas ao mundo! Isso faz de mim uma militante do bem-estar das mulheres!

A condição de ser professora, tendo alunas e alunos e a minha luta pela discriminação de gênero, fizeram-me perceber, de perto o quanto as estudantes são, a todo momento, "cortadas" pelos seus colegas homens, pelos professores e até por outras estudantes mulheres. As estudantes são muitas vezes ridicularizadas quando se pronunciam em sala de aulas e a maioria de seus colegas pensa que por serem mulheres, sáo intelectualmente inferiores e que elas não têm direito à palavra, quando eles o tem. Quando uma estudante respondesse a alguma questão com assertividade, os outros, mulheres e homens a encaravam como chata, a sábia, a que se acha, a que se faz de homem! Lógico que tratei de parar isso nas minhas aulas e passei a conversar e a agir tendo em conta a igualdade de gênero. Passei a indicar alunas e alunos para exercer tarefas de forma igualitária, como por exemplo, chefes de grupos. Era notório que poucos alunos aceitavam com tranquilidade a liderança de suas colegas, nos grupos. Alguns chegavam a contestar e a afirmar que não queriam ser dirigidas por mulheres.

O grande desapontamento foi verificar que as alunas aceitavam aquela discriminação de forma natural. Aceitavam o seu papel de sujeitas secundárias; de sujeitas que só existem depois dos homens! Dentro da sala de aula, por eu estar ali, parecia viver-se um ambiente igualitário, em que todos, alunos e alunas eram tratados com humanidade, mas a conformidade das alunas inconformou-me. Minha inconformidade resultou na criação do primeiro, grupo Sororidade, hoje associação.

Tive a ideia de criar o Grupo Sororidade num leve ataque de raiva por vivenciar discriminação dentro de uma universidade, onde devia ser o lugar da empatia, respeito, revolução e emancipação. E pensava, se não fosse as suas socializaçóes, minhas alunas e alunos conviveriam sem se discriminarem em função de seus gêneros, proveniência, etc. e somariam mais nos seus processos de aprendizagem e preparaçáo para o futuro.

Criei o Grupo Sororidade com uma primeira intenção de informar e formar mulheres sobre direitos humanos, sobre seus direitos e para de forma simples, dizerlhes que elas eram muito mais que aquele papel secundário que a sociedade havia-lhes imputado e que a universidade, a educação, porque patriarcal também, infelizmente continua(va) perpetuando em sala de aula e no seu recinto. Hoje o grupo tornou-se uma associação que defende a formação, transformação das mulheres e a igualdades de direitos, oportunidades dignidade e respeito pelas pessoas, sobretudo pelas mulheres e integram a associação 27 mulheres entre elas, minhas ex-alunas. 


\section{Lições a tirar sobre Covid-19, direitos das mulheres: em jeito de recomendação}

Diante do que já coloquei até aqui, avanço algumas sugestôes.

A primeira é que é preciso criar condiçôes para que as meninas ingressem mais nas escolas e tenham a possibilidade de continuar depois de concluir o ensino primário até o ensino universitário. Há que reforçar as políticas educativas para que as mulheres jovens tenham a possibilidade de adentrar as universidades, sem serem discriminadas pelo simples facto de serem mulheres. E que ao ingressar nas universitárias tenham espaço para se posicionar e não apenas para engrossar falsas estatísticas de igualdade de gênero, no país. Que a participação das mulheres seja de facto e que se visibilize em espaços de poder e de liderança dentro da universidade, tal como ocorre com os homens.

As políticas de pesquisa e docência devem ser igualitárias, pois percebe-se que apesar de a questáo da equidade de gênero estar plasmada em documentos da universidade e nos discursos de suas lideranças, na prática ainda se sente uma discriminação de gênero na atribuição de fundos para pesquisas e outras atividades.

É preciso igualmente começar a pautar pela temática do cuidado, sobretudo dentro da universidade. Pautar pela abordagem do cuidado fará com que a cultura do cuidado com o outro ofusque a discriminação de forma geral e a discriminação de gênero em particular. A temática da academia do cuidado é fundamental para o resgate da humanidade que perdemos e deu espaço à insensibilidade que impede um olhar de empatia pelo outro.

Para o caso de Moçambique, está claro que sem a contribuição das mulheres em tempos de pandemia o país colapsaria, pois são as mulheres que asseguram em grande parte, todo o cuidado como os outros, antes, durante e será assim depois da pandemia. Entáo, há toda uma necessidade de lançar um olhar humano à essa mulher e consequentemente aos seus direitos, sobretudo o direito a uma educação condigna e o de direito de viver livre de todo o tipo de violência e desprezo que se verificam atualmente e que influem, grandemente nos seus direitos humanos, como sujeitas de suas vidas (MONDLANE, 2011).

Freire (1996) ensina-nos, de forma didática e cuidadosa, a rejeitar todo o tipo de discriminação e que qualquer tipo de discriminação é uma transgressão à natureza humana, pois ninguém deve(ia) ter sua autonomia como sujeito a ser subjugada pela autonomia de outrem que é o que tem ocorrido, as sociedades subjugam continuamente a autonomia das mulheres, como sujeitas, fazendo com que elas vivam como seres humanos de segunda categoria.

Freire acrescenta que nenhuma discriminação deve ser vista como virtude, pois qualquer que seja o tipo de discriminação exerce, per si, uma ruptura com a decência. E remata: 
O que quero dizer é o seguinte: que alguém se torne machista, racista, classicista, sei lá o quê, mas que se assuma como transgressor da natureza humana. Não me venha com justificativas genéticas, sociológicas, históricas ou filosóficas para explicar a superioridade da branquitude sobre a negritude, dos homens sobre as mulheres, dos empregados sobre os empregados. Qualquer discriminação é imoral e lutar contra ela é um dever, por mais que se reconheça a força dos condicionalismos a enfrentar. A boniteza de ser gente se acha, entre outras coisas, nessa possibilidade e nesse dever de brigar (FREIRE, 1996, p. 30).

Todas estas questóes só serão conseguidas pelas e para as mulheres se se reconhecer que a educação delas é fundamental, portanto, enrobustecer políticas que incluam, de forma igualitária as mulheres e, para terminar, esta seção, precisase, igualmente, como diria Chimamanda Adichie, "precisamos encorajar mais mulheres a se atreverem a mudar o mundo".

\section{Considerações finais}

Como consideraçóes finais, gostaria de destacar que o direito à educação é um direito universal, como tal, de todos os seres humanos, incluindo as mulheres. O exposto neste texto mostrou, por um lado que em Moçambique, a mulher é discriminada desde cedo e convive com essa realidade violenta ao longo de sua vida, não sendo diferente em tempos de crise como a pandemia da Covid-19 e por outro, essa mesma mulher tem contribuído na educação familiar, escolar e social, para além do cuidado que dedica aos outros.

Urge que as sociedades aprendam a cuidar dessa mulher e respeitar. Precisamos cuidar de quem cuida, pois sem o cuidado com os outros, incluindo com a mulher, com as instituiçóes, com a natureza e com o futuro, não teremos futuro, ou seja "tudo passa pelo cuidar - cuidar de si mesmo, dos outros, das instituiçôes e do planeta. [...], não vamos achar solução para os problemas que nos afligem, sejam eles educacionais, políticos ou ambientais, se não substituirmos o paradigma de dominação, poder e consumo por um paradigma de cuidado, empatia e respeito. Isso pressupóe um novo entendimento sobre praticamente tudo, inclusive sobre a Educaçáa" (TORO, apud DINIZ, 2019, p.). Na mesma esteira, é preciso conceber a educação como prática da liberdade para todos os cidadãos e cidadãs, um tipo de educação desprovida de alienação e que seja baseada na mudança e na liberdade das pessoas, incluindo mulheres, terem a possibilidade de viver de forma digna, sendo sujeitas de suas vidas. (FREIRE, 1999). E que lembremos, reflitamos e aprendamos com Paulo Freire, o eterno professor: não se pode falar de educação sem amor! 


\section{Referências}

AVIZ, R. e NHAMPOCA, E. As negras vozes e o empoderamento do feminino na escrita de Lília Momplé. In 13o Mundos de Mulheres e Fazendo gênero 11, 2017. Anais. Florianópolis: UFSC, 2017, p. 1-12. Disponível em http://www.en.wwc2017.eventos.dype.com.br/resources/anais/1499480241_ ARQUIVO_FAZENDOGENEROTEXTOCOMPLETO2017REVJO.pdf. Acesso em: 12 fev. 2021.

DINIZ, A. M. A Pedagogia do cuidado. Estadáo, São Paulo, 30 de Maio de 2019. Disponível em: https://educacao.estadao.com.br/blogs/ana-maria-diniz/apedagogia-do-cuidado/. Acesso em: 13 fev. 2021.

FREIRE, P. Educaçáo como prática da liberdade. 23. ed. São Paulo: Paz e Terra, 1999. $158 \mathrm{p}$.

FREIRE, P. Pedagogia da autonomia: saberes necessários à prática educativa. 25. ed. São Paulo: Paz e Terra, 1996.76 p.

INSTITUTO NACIONAL DE ESTATÍSTICA - MOÇAMBIQUE. Dados do Recenseamento Geral da Populaçáo de 2019. Disponível em http://www.ine. gov.mz/. Acesso em: 12 fev. 2021.

LIMA, N. A pandemia não é a mesma para todos. [Entrevista concedida a ECOA]. Eduardo Ribeiro. Ecoa por um mundo melhor, São Paulo, jul. 2020. Disponível em https://www.uol.com.br/ecoa/ultimas-noticias/2020/07/06/ a-pandemia-nao-e-a-mesma-para-todos-diz-a-presidente-da-fiocruz. htm?cmpid=copiaecola Acesso em: 26 nov. 2020.

MOÇAMBIQUE. MINISTÉRIO DA EDUCAÇÃO, Direção para a coordenação do ensino superior. Relatório do estudo sobre gênero no ensino superior em Moçambique: 2013. Maputo, 2013. 42 p. disponível em https:// www.isutc.ac.mz/wp-content/uploads/2017/05/Estudo-sobre-Genero-noEnsino-Superior.pdf . Acesso em: 15 fev. 2021.

MOMPLÉ, L. Os olhos da cobra verde. Maputo: Associação dos Escritores Moçambicanos, 1997. 96 p.

MONDLANE, C. Lei de promoçáo e proteçáo dos direitos da criança. Edição anotada e comentada. Maputo: Ministério da Justiça - Centro de Formação Jurídica e Jurídica, 2011, 349. 
NHAMPOCA, E. Ezra Nhampoca defende a redução do fardo imputado às mulheres na vida conjugal. [Entrevista concedida ao Jornal Generus]. Evaristo Taimo. Jornal Generus, Maputo, 28a ed. (p. 4 -6), fev. 2021.

NHAMPOCA, J. A Strategic alignment framework for the prevention and combat of early marriage and maternity in Zambézia province, Mozambique. $2020.261 \mathrm{f}$. Tese de (Doutoramento em estudos de saúde, University of South Africa, Pretória, 2020.

NHAMPOCA, J. Violência doméstica em tempos de isolamento social: uma interpretação das estatísticas criminais. 2020. No Prelo.

UNIVERSIDADE EDURADO MONDLANE. Página web oficial. Estatísticas sobre docentes. Disponível em https:/www.uem.mz/index.php/90-sobrea-uem/uem-em-numeros/uem-em-numeros-2012/203-estatisticas-sobredocentes?mid=151\&limit-start=115. Acesso em: 13 fev. 2021. 